\section{D) Check for updates}

Cite this: DOI: 10.1039/c9fo01731c

\title{
Ageing, dehulling and cooking of Bambara groundnuts: consequences for mineral retention and in vitro bioaccessibility $\dagger$
}

\author{
Shannon Gwala, (D) Clare Kyomugasho, Irene Wainaina, (D) Sofie Rousseau, (D) \\ Marc Hendrickx (D) and Tara Grauwet (D) *
}

\begin{abstract}
Postharvest storage of legumes is a strategy to ensure food security. However, the hard-to-cook phenomenon, partly explained by pectin-cation-phytate theory, may develop during storage. Based on this theory, minerals could be redistributed within the matrix, affecting the concentration of free/bound minerals and hence their bioaccessibility. Therefore, this study investigated the influence of storage-induced ageing and subsequent dehulling, soaking and cooking treatments on the concentration and in vitro bioaccessibility of $\mathrm{Ca}, \mathrm{Mg}$, Fe and $\mathrm{Zn}$ in Bambara groundnuts. ICP-OES was performed to determine $\mathrm{Ca}, \mathrm{Mg}$, Fe and Zn concentrations after applying different treatments and after simulated digestion in the context of bioaccessibility determination. This study illustrates that while the seed coat is rich in Ca (51\%), it contains only less than $15 \%$ of $\mathrm{Mg}$, Fe or Zn. Hence, dehulling negatively influenced $\mathrm{Ca}$, but not $\mathrm{Mg}$, Fe or Zn concentration. During soaking, up to $10 \%$ or $56 \%$ of the initial Mg concentration leaches into whole or dehulled seeds, respectively. Prolonging the cooking time (300 min) of whole aged Bambara groundnuts (32 weeks), necessary for obtaining palatable textures, decreased the overall $\mathrm{Mg}$, Fe and $\mathrm{Zn}$ concentrations by $72 \%, 57 \%$ and $48 \%$, respectively. Storage-induced ageing significantly decreased $\mathrm{Ca}$ solubility and bioaccessibility. Bioaccessibility of trace minerals in Bambara groundnuts is low, especially for Fe, and cannot be improved by dehulling or cooking treatments. Ageing did not influence Fe and Zn bioaccessibility. Populations relying

on both fresh and aged Bambara groundnuts may still be at risk for mineral deficiencies.
\end{abstract}

\author{
Received 31st July 2019, \\ Accepted 11th February 2020 \\ DOI: 10.1039/c9fo01731c \\ rsc.li/food-function
}

\section{Introduction}

Dietary minerals play a crucial role in sustaining human life as they are involved in numerous biochemical pathways. ${ }^{1,2}$ As such, a diet rich in minerals is vital, given that the body cannot synthesise them on its own. After meal ingestion, minerals must be released from the food matrix to enable their absorption across the epithelial cells that line the gastrointestinal (GI) tract. ${ }^{3}$ However, minerals in food do not always exist in a bioaccessible state and can be bound to several antinutrients, for instance, phytates, polyphenols, oxalates and pectin present in most plant-based food. The presence of these indigestible mineral-antinutrient complexes potentially limits mineral bioaccessibility. ${ }^{4-6}$

KU Leuven, Department of Microbial and Molecular Systems $\left(M^{2} S\right)$, Leuven Food Science and Nutrition Research Centre (LFoRCe), Laboratory of Food Technology, Kasteelpark Arenberg 22, PB 2457, 3001, Leuven, Belgium.

E-mail: shannon.gwala@kuleuven.be, tara.grauwet@kuleuven.be

$\dagger$ Electronic supplementary information (ESI) available. See DOI: 10.1039/ c9fo01731c
Several studies have investigated the bioaccessibility of minerals in legumes (e.g., common beans, cowpeas, chickpeas and lentils) after processing. ${ }^{7-9}$ However, little attention has been paid to the influence of postharvest storage-induced changes. In reality, the storage of legumes in most developing countries is largely uncontrolled, yet the climate there is hot and humid. Besides, the storage period between two harvesting seasons can easily reach 6-12 months or longer. Under such storage conditions $\left(>25{ }^{\circ} \mathrm{C}\right.$ and $\left.65 \% \mathrm{RH}\right)$, the hard-to-cook phenomenon (HTC) is most likely to develop. ${ }^{10}$ Of the widely accepted hypotheses explaining the HTC phenomenon, pectin-cationphytate theory has received much attention. In this theory, phytase dephosphorylates the potent mineral chelator phytic acid $\left(\mathrm{IP}_{6}\right)$ to lower inositol phosphates $\left(\mathrm{IP}_{5,4,3,2}\right)$. These possess less mineral chelating ability compared to $\operatorname{IP}_{6} \cdot{ }^{11,12}$ When dephosphorylation of phytic acid occurs, some minerals are released. Alongside this reaction, pectin is demethylesterified by pectin methylesterase as ageing continues, enhancing its ability to chelate cations. ${ }^{13}$ The demethylesterified pectin could bind the released ions, potentially leading to the formation of crosslinks that strengthen the pectin-rich middle lamella of plant cell walls. ${ }^{14}$ This mechanism implies that 
there is a redistribution of minerals within the cotyledon matrix where this phenomenon occurs.

Following postharvest storage of legumes, there is always some level of processing, which can alter the matrix on different scales. Milling, for example, can cause a redistribution of minerals and antinutrients compartmentalised in different substructures of the seed. ${ }^{4}$ Dehulling is a simple pre-processing step that may decrease the content of antinutrients, for instance, tannins. ${ }^{15}$ The cooking of whole or dehulled legume seeds, after a soaking step, is the most common household processing step. A general belief is that minerals leach into the soaking or cooking water, ${ }^{8,16}$ yet it is not clear to what extent this happens and whether this is inferable to all minerals. Moreover, the influence of other factors such as storage or dehulling on the degree of leaching is still an open question.

Most studies concerning mineral bioaccessibility of legumes focus on globally marketed sources such as common beans, chickpeas and lentils. ${ }^{7,9,17}$ Nonetheless, it is crucial to gain this knowledge for other legume types. These legumes may not necessarily have a global market share but are of key importance in the regions where they are grown, chiefly in the context of food security. Bambara groundnuts (Vigna subterranea) were selected for this study, first because they are relied on to provide nutrition to famine prone rural populations, due to their drought-tolerance and high nutrient-density. ${ }^{15,18}$ Bambara groundnuts are reported to be a rich source of minerals. A serving of $100 \mathrm{~g}$ is calculated to potentially provide more than $50 \%$ of the recommended daily allowance of $\mathrm{K}, \mathrm{Mg}$ and $\mathrm{Zn} .{ }^{19}$ However, initial mineral concentrations do not always provide a good indication of the true bioaccessible amounts. ${ }^{9,20}$ Second, several antinutrients, for instance, polyphenols, phytates and pectin are present in Bambara groundnuts. ${ }^{21}$ Notably, these antinutrients, e.g., phytates and pectin, which can limit mineral bioaccessibility, also participate in the described mechanism of the pectin-cation-phytate hypothesis of the HTC phenomenon. ${ }^{22,23}$ As such, there is a need to investigate the consequences of storage-induced ageing on mineral bioaccessibility.

The goal of this study was, first, to evaluate the evolution of the concentration of the selected minerals during storage (distribution between the seed coat and the cotyledon) and after subsequent dehulling, soaking and cooking treatments. Second, this work aimed to provide insight into the effects of these treatments on the in vitro bioaccessibility of the selected minerals using Bambara groundnuts as a model legume. $\mathrm{Ca}$ and $\mathrm{Mg}$ were selected as macro-elements which are essential in the diet and at the same time interact with the antinutrients pectin and phytates to different degrees. ${ }^{24}$ The trace elements $\mathrm{Fe}$ and $\mathrm{Zn}$ were selected as theirs are the most widespread deficiencies ${ }^{25}$ and they may be highly chelated by phytates and pectin as well. ${ }^{26}$

\section{Materials and methods}

\subsection{Description of the plant material and prepared samples}

Fresh (dry) Bambara groundnuts were obtained from communal farmers in the Masvingo Province in Zimbabwe after the harvesting season of 2016. On arrival at the laboratory, the groundnuts were sorted to remove foreign matter and any damaged seeds. A part of the cleaned Bambara groundnuts was then kept at $-40{ }^{\circ} \mathrm{C}$ and this represented the fresh sample (denoted 0 weeks). Another part of this batch was stored for 16 and 32 weeks, under the conditions of $35{ }^{\circ} \mathrm{C}$ and $78 \% \mathrm{RH}$ aimed at inducing the hard-to-cook phenomenon (ageing) as established in our previous study which used the same batch of Bambara groundnuts. ${ }^{27}$

A part of the fresh and aged samples was soaked and cooked whole. The other part was manually dehulled with a knife before soaking and cooking. Dehulling was included because it may favourably reduce the concentrations of some antinutrients, including those which are mineral chelating. ${ }^{15}$ Soaking was done by immersing the seeds in distilled water $\left(1: 5\right.$ ratio w/v) for $16 \mathrm{~h}$ at $25^{\circ} \mathrm{C}$. The soaking water was decanted and evaporated to account for solute loss.

The soaked samples were placed in individual Duran bottles with fresh preheated $\left(95^{\circ} \mathrm{C}\right)$ distilled water $(1: 5 \mathrm{w} / \mathrm{v})$ and were cooked for 60 or $120 \mathrm{~min}$. Cooking times of 60 and 120 min were selected as they represent the upper and lower palatable hardness levels of the fresh sample ( 0 weeks). Since aged Bambara groundnuts need longer cooking time to sufficiently soften, the cooking time for the aged samples was also adapted (180 min for 16 weeks and 300 min for 32 weeks) to prepare samples with a palatability level equivalent to that of the fresh sample ( 0 weeks-120 min). Palatability levels were already known for this batch from our previous study, ${ }^{27}$ where the texture of the same Bambara groundnuts batch prepared under the same conditions was determined.

The cooked samples were mashed with a mortar and pestle to disintegrate the sample before digestion. Raw samples were milled with a bench mill (IKA Labortechnik - A10, Germany). All prepared samples were freeze-dried and kept in a desiccator until further use. Freeze-drying was assumed to not affect the minerals or the structure of the samples. All chemicals and reagents used were of analytical grade.

\subsection{Determination of the degree of methylesterification}

Fourier transform infrared spectroscopy (FT-IR) was used to determine the degree of methylesterification (DM) of pectin of the fresh and aged Bambara groundnuts. Transverse sections, $40 \mu \mathrm{m}$ thick, of 4 seeds of the fresh and aged cotyledons (soaked), were cut using a manual sliding microtome after freezing them on a cryo-stage. The sections were cleaned several times with water using a brush to eliminate starch and protein from within the cell walls. The sections were then stored in $70 \%$ ethanol until use.

For FT-IR measurements, each section (3 sections for each seed) was placed on parafilm and allowed to dry. The dry section was placed on the sample holder of the FT-IR, and the transmittance of the sample was measured in the range of $4000 \mathrm{~cm}^{-1}$ to $400 \mathrm{~cm}^{-1}$. Integrated spectral mean values of 100 scans were collected per sample at a resolution of $4 \mathrm{~cm}^{-1}$. After pre-processing of the spectra, the absorption intensity of the bands located at around $1740 \mathrm{~cm}^{-1}$ (due to ester carbonyl 
group (C-O) stretching) and 1630-1600 $\mathrm{cm}^{-1}$ (due to carboxylate group (COO-) stretching) were obtained. The DM was calculated as $136.86 x+3.987$, where $x$ is the ratio of the intensity of the ester carbonyl band to the sum of the intensities of the ester carbonyl band and the carboxylate group. ${ }^{28}$

\subsection{Determination of mineral concentrations}

Before mineral concentration determination, the whole, dehulled seeds and the seed coats were subjected to ashing to incinerate all the organic matter. ${ }^{29}$ Ten $\mathrm{mg}$ of powder was ashed in a muffle furnace at $550{ }^{\circ} \mathrm{C}$ for $20 \mathrm{~h}$. This was performed in triplicate for each sample. After cooling, the obtained ash was dissolved in $9.9 \mathrm{~mL}$ of Milli-Q water, and $0.1 \mathrm{~mL}$ of $65 \%$ nitric acid was added. The solution was left to stand at room temperature overnight. The next day, the samples were filtered using a $0.45 \mu \mathrm{m}$ membrane filter (Chromaphil@ A-45/25, Macherey-Nagel, Germany) and were analysed using inductively coupled plasma optical emission spectroscopy (ICP-OES). The $\mathrm{Mg}, \mathrm{Ca}, \mathrm{Fe}$ and $\mathrm{Zn}$ contents in the ashed samples or the aliquots of the soluble or bioaccessible fraction (sections 2.4 and 2.6, respectively) were measured using an iCAP 7400 ICP-OES Duo spectrometer (USA). $\mathrm{Mg}$ and Ca were measured radially at $285 \mathrm{~nm}$ and $318 \mathrm{~nm}$, respectively, while Fe and Zn were measured axially at $238 \mathrm{~nm}$ and $206 \mathrm{~nm}$. Two certified reference materials BCR-129 and BCR-679 (Joint Research Centre, European Commission) were ashed and analysed as described above and good recoveries were obtained (Table S1 $\dagger$ ). Calibration was performed using SPS-SW2, before each run and after measuring 20 samples. The mineral content was expressed as mg per $100 \mathrm{~g}$ dry weight (dw).

\subsection{Determination of soluble minerals}

To determine the content of soluble minerals $500 \mathrm{mg}$ of milled and freeze-dried sample of the raw fresh or aged Bambara groundnut flour was dispersed in $10 \mathrm{~mL}$ of Milli-Q water ( $\mathrm{pH} 7) .{ }^{9}$ After $2 \mathrm{~h}$ of continuous stirring, the samples were centrifuged, and the supernatant was assessed for the soluble $\mathrm{Ca}, \mathrm{Mg}$, Fe and $\mathrm{Zn}$ contents as described in section 2.3. The solubility was calculated as follows:

$$
\begin{aligned}
& \text { Soluble mineral }(\%) \\
& =\frac{\text { concentration in the supernatant }}{\text { concentration in the sample }} \times 100 \%
\end{aligned}
$$

\subsection{Fluorescence microscopy of labelled $\mathrm{Ca}$-pectin crosslinks}

Fresh and aged cotyledon sections $(40 \mu \mathrm{m})$ were treated with the monoclonal antibody 2F4 (PlantProbes, Leeds, United Kingdom), which is specific for $\mathrm{Ca}$ crosslinked regions of pectin. $^{30}$ Exactly $30 \mu \mathrm{L}$ of a ten-fold dilution of $2 \mathrm{~F} 4$ in $3 \%$ milk-saline phosphate buffer was added to the sections in a Petri dish, and incubated at $28^{\circ} \mathrm{C}$ for $1.5 \mathrm{~h}$. Later, the sections were washed for $5 \mathrm{~min}$ in phosphate buffer ( 3 times) to remove the excess unbound antibody. For visualisation, anti-mouse immunoglobulin G secondary antibody coupled with fluorescein (diluted 50 times) in $3 \%$ milk phosphate buffer was added to the sections. The sections were incubated for $1 \mathrm{~h}$ at $28{ }^{\circ} \mathrm{C}$ in a dark environment. ${ }^{31}$ After this, the sections were washed 3 times in phosphate buffer for $5 \mathrm{~min}$ each cycle. The samples were then viewed under epifluorescence light (excitation filter between 460 and $490 \mathrm{~nm}$ ) using an Olympus BX-51 microscope equipped with epifluorescence illumination (X-Cite ${ }^{\circledR}$ 120Q, X-Cite ${ }^{\circledR}$ Fluorescence Illumination, EXFO Europe, UK). Images were viewed at $\times 40$ magnification using a photo-analysing software (CellF®) after ensuring that there was no background autofluorescence.

\subsection{In vitro digestion protocol}

Simulated in vitro digestion of whole and dehulled Bambara groundnuts was performed using the INFOGEST protocol. ${ }^{32}$ Briefly, for the oral phase, freeze-dried samples were first reconstituted to their original moisture content after cooking with distilled water to obtain $1.25 \mathrm{~g}$ as the starting weight. After this, $1 \mathrm{~mL}$ of simulated salivary fluid (SSF) electrolyte stock solution, $0.125 \mathrm{~mL}$ of $0.015 \mathrm{M} \mathrm{CaCl}_{2}$ solution and $0.125 \mathrm{~mL}$ of demineralised water were added and mixed. Next, precisely $1.6 \mathrm{~mL}$ of simulated gastric fluid (SGF) and $0.025 \mathrm{~mL}$ of $\mathrm{CaCl}_{2}(0.015 \mathrm{M})$ were pipetted into the $2.5 \mathrm{~mL}$ oral bolus. The mixture was adjusted to $\mathrm{pH} 3$ using $\mathrm{HCl}$, and then $0.4 \mathrm{~mL}$ of porcine pepsin (Sigma P7012) dissolved in SGF solution was added to achieve $2000 \mathrm{U} \mathrm{mL}^{-1}$ in the final digestion mixture. The mixture was incubated at $37^{\circ} \mathrm{C}$ for $2 \mathrm{~h}$ (with end-over-end rotation at $40 \mathrm{rpm}$ ) to simulate the gastric digestion phase.

For the small intestinal phase, the following solutions were added: $2.75 \mathrm{~mL}$ of simulated intestinal fluid (SIF), $0.2 \mathrm{~mL}$ $\mathrm{CaCl}_{2}(0.015 \mathrm{M})$ and $0.625 \mathrm{~mL}$ of bile freshly dissolved in water (final concentration of $10 \mathrm{mM}$ ). The $\mathrm{pH}$ of the mixture was adjusted to 7 , and next, $1.25 \mathrm{~mL}$ of pancreatic enzymes (pancreatin - Sigma P1750; chymotrypsin - Sigma C4129; trypsin Sigma T2011) dissolved in SIF was added. The added enzyme volume resulted in $200 \mathrm{U} \mathrm{mL}^{-1}$ of pancreatic amylase, $100 \mathrm{U}$ $\mathrm{mL}^{-1}$ of trypsin, and $25 \mathrm{U} \mathrm{mL}^{-1}$ of chymotrypsin. The samples were immediately incubated at $37^{\circ} \mathrm{C}$ with end-over-end rotation at $40 \mathrm{rpm}$. Preliminary data showed that during the small intestinal phase, mineral bioaccessibility was independent of digestion time. Therefore, only the endpoint determinations at $2 \mathrm{~h}$ of the small intestinal digestion phase were considered. At least 2 cycles of digestion were performed for each sample. The samples were heat shocked $\left(100^{\circ} \mathrm{C}\right)$ to deactivate the enzymes and to stop digestion. The digests were centrifuged, and the supernatant was collected and frozen until use. The mineral concentrations were analysed, as described in section 2.3. Mineral bioaccessibility was then calculated as shown in eqn (2). For the blank, we replaced the sample weight with $1.25 \mathrm{~mL}$ distilled water, and all the other steps were followed as described above.

$$
\begin{aligned}
& \text { Mineral bioaccessibility }= \\
& \frac{\text { mineral conc. in the digest }- \text { conc. in the blank }}{\text { mineral conc. in the sample }} \times 100 \%
\end{aligned}
$$




\subsection{Estimation of contribution towards the recommended nutrient intake}

The contribution of a $130 \mathrm{~g}$ serving (wet basis) of fresh and aged Bambara groundnuts towards the recommended nutrient intake (RNI) of $\mathrm{Ca}, \mathrm{Mg}, \mathrm{Fe}$ and $\mathrm{Zn}$ per day was calculated. Since a population has groups with different RNI requirements, the RNI of the group needing the most amount per day was considered. For $\mathrm{Ca}$, the RNI of $1000 \mathrm{mg} \mathrm{day}^{-1}$ as required by an adolescent was used and for $\mathrm{Mg}$, the RNI of $260 \mathrm{mg}$ day $^{-1}$ as required by an average adult male was used. ${ }^{33}$ For $\mathrm{Zn}$, the RNI of $12 \mathrm{mg} \mathrm{day}^{-1}$ for pregnant women was used (assuming that they regularly consume a diet with low $\mathrm{Zn}$ bioavailability). For Fe, the RNI of $21.8 \mathrm{mg}$ day $^{-1}$ as required by 11-14 year old females who regularly consume a diet with low Fe bioavailability was considered. ${ }^{33}$

\subsection{Data analysis}

The effects of ageing and subsequent steps of dehulling, soaking and cooking time on $\mathrm{Ca}, \mathrm{Mg}$, Fe and $\mathrm{Zn}$ concentrations and bioaccessibility were assessed. Regression analysis (least squares approach) was used to evaluate the treatments that were significant in influencing the concentration or bioaccessibility of a particular mineral, through the Fit model platform of JMP® (version 14.0.0, SAS Institute, Inc., Cary, NC, USA). Non-significant variables were excluded from the final model or only included if their exclusion caused a lack of fit or reduced the $R^{2}$ adj. The model was assessed by the lack of fit test and by evaluating residuals and QQplots. ANOVA was used to analyse the solubility results.

\section{Results and discussion}

In this work, we investigated the effect of storage-induced ageing, dehulling, soaking and cooking on the concentration levels of $\mathrm{Ca}$ and $\mathrm{Mg}$ as macro-elements and $\mathrm{Fe}$ and $\mathrm{Zn}$ as trace elements (section 3.1). In plant-based materials, minerals are not necessarily free. We studied the complexation of the selected minerals as affected by storage-induced ageing, discussed in section 3.2. Finally, treatment effects of storage, dehulling and cooking on mineral bioaccessibility levels are evaluated (section 3.3).

\subsection{Concentration of $\mathrm{Ca}, \mathrm{Mg}$, Fe and $\mathrm{Zn}$ as affected by treatments}

3.1.1 Influence of storage-induced ageing. There was limited variability in the concentration of the minerals in raw seeds over the ageing time as explored in this study: Ca (47.7-49.9 mg per $100 \mathrm{~g} \mathrm{dw}$ ), Mg (166.9-169.6 mg per $100 \mathrm{~g}$ $\mathrm{dw})$, Fe (4.6-4.9 $\mathrm{mg}$ per $100 \mathrm{~g} \mathrm{dw}$ ) and $\mathrm{Zn} \mathrm{(3.1-3.8} \mathrm{mg}$ per $100 \mathrm{~g} \mathrm{dw}$ ) (Table 1). Since there was no dry matter loss with storage time, the result is not surprising. Similarly, little variation in the concentration of these minerals in the seed coat was observed with ageing (Table 2), implying that there was limited migration of minerals between the seed coat and the cotyledon during storage. In fact, in mature seeds, the vascular
Table 1 Concentration of $\mathrm{Ca}, \mathrm{Mg}, \mathrm{Fe}$ and $\mathrm{Zn}$ in the 0,16 and 32 weeks stored whole and dehulled Bambara groundnuts, when raw and after soaking and cooking treatments. Values are means $(n=3) \pm$ standard deviation

\begin{tabular}{|c|c|c|c|c|}
\hline Sample & Raw & Soaking & $\begin{array}{l}60 \text { min } \\
\text { cooking }\end{array}$ & $\begin{array}{l}120 \mathrm{~min} \\
\text { cooking }\end{array}$ \\
\hline \multicolumn{5}{|c|}{$\mathrm{Ca}(\mathrm{mg}$ per $100 \mathrm{~g} \mathrm{dw})$} \\
\hline 0 week-whole & $49.9 \pm 3.2$ & $48.8 \pm 1.1$ & $49.8 \pm 6.1$ & $48.3 \pm 5.8$ \\
\hline 0 week-dehulled & $32.2 \pm 2.4$ & $31.8 \pm 0.7$ & $24.2 \pm 5.2$ & $23.4 \pm 3.9$ \\
\hline 16 week-whole & $47.3 \pm 1.4$ & $46.7 \pm 0.4$ & $45.0 \pm 6.1$ & $51.0 \pm 3.7$ \\
\hline 16 week-dehulled & $32.8 \pm 3.0$ & $31.3 \pm 1.0$ & $22.2 \pm 6.8$ & $19.5 \pm 2.2$ \\
\hline 32 week-whole & $47.7 \pm 5.8$ & $49.1 \pm 2.9$ & $50.3 \pm 3.7$ & $49.6 \pm 7.1$ \\
\hline 32 week-dehulled & $31.2 \pm 1.9$ & $30.1 \pm 0.7$ & $21.4 \pm 2.2$ & $20.7 \pm 1.3$ \\
\hline \multicolumn{5}{|c|}{$\mathrm{Mg}(\mathrm{mg}$ per $100 \mathrm{~g}$ dw) } \\
\hline 0 week-whole & $166.9 \pm 5.1$ & $164.2 \pm 1.9$ & $139.3 \pm 2.8$ & $122.9 \pm 7.3$ \\
\hline 0 week-dehulled & $188.8 \pm 14.7$ & $119.4 \pm 2.7$ & $87.7 \pm 5.9$ & $62.9 \pm 7.8$ \\
\hline 16 week-whole & $167.8 \pm 1.9$ & $150.7 \pm 1.1$ & $104.9 \pm 4.7$ & $108.8 \pm 10.3$ \\
\hline 16 week-dehulled & $182.0 \pm 7.0$ & $116.5 \pm 7.2$ & $66.4 \pm 1.4$ & $58.9 \pm 6.0$ \\
\hline 32 week-whole & $169.6 \pm 8.5$ & $152.1 \pm 11.5$ & $95.5 \pm 1.3$ & $94.5 \pm 6.7$ \\
\hline 32 week-dehulled & $187.9 \pm 2.4$ & $82.3 \pm 6.9$ & $56.0 \pm 1.2$ & $49.8 \pm 0.9$ \\
\hline \multicolumn{5}{|c|}{$\mathrm{Fe}(\mathrm{mg}$ per $100 \mathrm{~g} \mathrm{dw})$} \\
\hline 0 week-whole & $4.9 \pm 0.1$ & $3.8 \pm 0.3$ & $3.6 \pm 0.1$ & $3.4 \pm 0.1$ \\
\hline 0 week-dehulled & $4.3 \pm 0.1$ & $3.7 \pm 0.2$ & $3.5 \pm 0.1$ & $3.1 \pm 0.2$ \\
\hline 16 week-whole & $4.6 \pm 0.1$ & $3.6 \pm 0.1$ & $3.3 \pm 0.4$ & $3.2 \pm 0.1$ \\
\hline 16 week-dehulled & $4.9 \pm 0.2$ & $3.5 \pm 0.1$ & $3.4 \pm 0.1$ & $2.7 \pm 0.3$ \\
\hline 32 week-whole & $4.7 \pm 0.2$ & $3.4 \pm 0.1$ & $3.2 \pm 0.5$ & $3.3 \pm 0.5$ \\
\hline 32 week-dehulled & $4.4 \pm 0.3$ & $3.5 \pm 0.1$ & $3.3 \pm 0.1$ & $2.7 \pm 0.4$ \\
\hline \multicolumn{5}{|c|}{$\mathrm{Zn}(\mathrm{mg}$ per $100 \mathrm{~g} \mathrm{dw})$} \\
\hline 0 week-whole & $3.1 \pm 0.1$ & $2.8 \pm 0.1$ & $3.0 \pm 0.1$ & $2.2 \pm 0.1$ \\
\hline 0 week-dehulled & $3.2 \pm 0.2$ & $2.9 \pm 0.1$ & $2.8 \pm 0.1$ & $2.6 \pm 0.1$ \\
\hline 16 week-whole & $3.2 \pm 0.6$ & $3.0 \pm 0.1$ & $2.8 \pm 0.5$ & $2.5 \pm 0.1$ \\
\hline 16 week-dehulled & $3.2 \pm 0.2$ & $2.9 \pm 0.1$ & $2.5 \pm 0.1$ & $2.2 \pm 0.2$ \\
\hline 32 week-who & $3.8 \pm 0.7$ & $2.9 \pm 0.1$ & $2.5 \pm 0.2$ & $2.3 \pm 0.3$ \\
\hline 32 week-dehulled & $3.3 \pm 0.2$ & $2.9 \pm 0.1$ & $2.3 \pm 0.1$ & $2.2 \pm 0.1$ \\
\hline
\end{tabular}

Table 2 Concentration of $\mathrm{Ca}, \mathrm{Mg}, \mathrm{Fe}$ and $\mathrm{Zn}$ in the seed coat of Bambara groundnuts. Values are means $(n=3) \pm$ standard deviation

\begin{tabular}{|c|c|c|c|c|}
\hline \multirow[b]{2}{*}{ Storage time (weeks) } & \multicolumn{4}{|c|}{$\begin{array}{l}\text { Mineral content of the seed coat } \\
(\mathrm{mg} \text { per } 100 \mathrm{~g} \mathrm{dw})\end{array}$} \\
\hline & $\mathrm{Ca}$ & $\mathrm{Mg}$ & $\mathrm{Fe}$ & $\mathrm{Zn}$ \\
\hline 0 & $302.0 \pm 22.4$ & $311.6 \pm 1.7$ & $6.8 \pm 0.7$ & $3.8 \pm 0.1$ \\
\hline 16 & $315.8 \pm 13.1$ & $298.7 \pm 4.2$ & $7.5 \pm 1.0$ & $3.3 \pm 0.1$ \\
\hline 32 & $303.7 \pm 20.0$ & $330.6 \pm 6.4$ & $7.1 \pm 0.1$ & $3.1 \pm 1.2$ \\
\hline $\begin{array}{l}\text { Relative contribution } \\
(\%) \text { of the seedcoat to } \\
\text { the } \mathrm{Ca}, \mathrm{Mg} \text {, Fe or } \mathrm{Zn} \\
\text { concentration }\end{array}$ & $51 \%$ & $14 \%$ & $12 \%$ & $7 \%$ \\
\hline
\end{tabular}

connections between the seed coat and filial tissues (embryo and endosperm) cease to exist. ${ }^{34}$

3.1.2 Influence of dehulling. Dehulling decreased the concentration of $\mathrm{Ca}$ by $33 \%$, while the concentration of $\mathrm{Mg}, \mathrm{Fe}$ or Zn was only marginally changed (Table 1 ). This observation was statistically proven by the integrated data analysis performed to establish the effect of the different treatments considered (i.e. storage time, dehulling, soaking and cooking) per mineral type (Table 3 ). In this table, the higher the value of a coefficient (positive or negative), the greater the effect of the 
Table 3 Regression coefficients ( \pm error) of the variables (storage time, dehulling, soaking and cooking treatments) influencing Ca, Mg, Zn and Fe concentration. Significance was tested at $95 \%$ confidence intervals

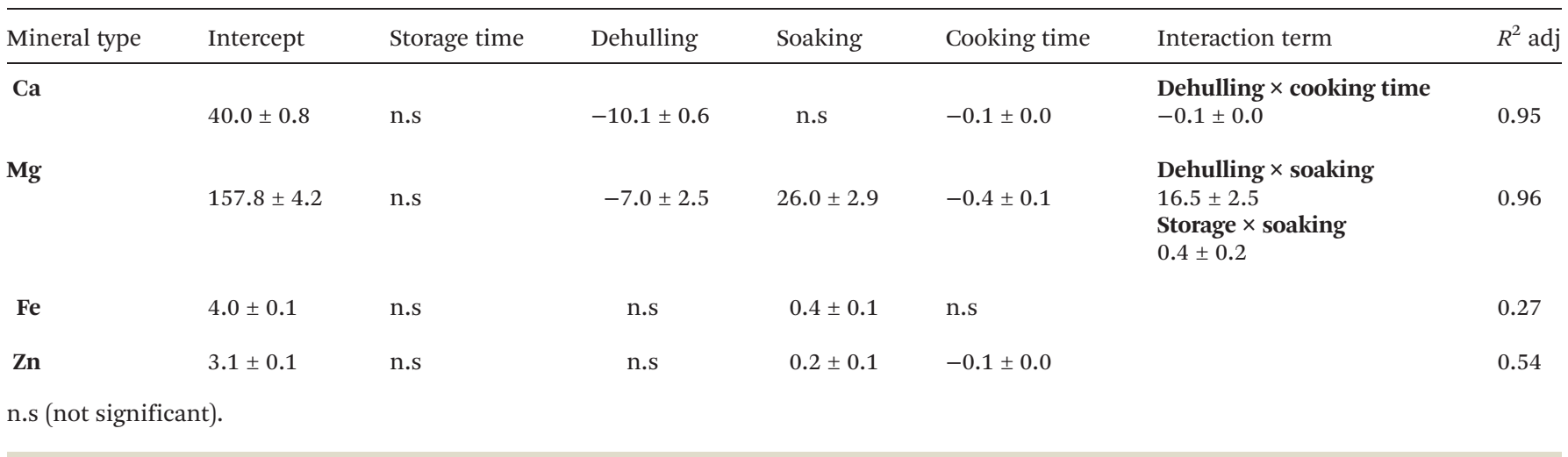

treatment. Intercept values represent average concentrations determined for all types of raw samples (Table 1). For Ca, dehulling was the most significant main effect influencing the Ca concentration (Table 3). The seed coat was only 8.2\% (dry weight) of a whole Bambara groundnut seed but contributed about $51 \%$ to the total Ca concentration (Table 2). According to the literature, the accumulation of $\mathrm{Ca}$ in the seed coat is attributed to its restricted movement from the seed coat to the cotyledon during seed development due to the formation of insoluble Ca oxalates in the seed coat. ${ }^{35,36}$ The same trend was reported in white and mottled common bean varieties, where $70 \%$ of total Ca was associated with the seed coat. ${ }^{37}$

In contrast, dehulling was not a significant main effect influencing the concentration of $\mathrm{Mg}$, Fe or $\mathrm{Zn}$ (Table 3). Although these minerals were also present in the seed coat, their relative contribution to the total concentration was lower $(<15 \%)$ compared to that of $\mathrm{Ca}(51 \%)$ (Table 2$)$. From these results, it could be deduced that most of the $\mathrm{Mg}$, Fe and $\mathrm{Zn}$ present in Bambara groundnuts is associated with the cotyledon. These results agree with a study that illustrated that the seed coat of common beans (black) contributed to the lower relative percentages of $\mathrm{Mg}, \mathrm{Zn}$ and $\mathrm{Fe}(16 \%, 7 \%$ and $14 \%$, respectively). ${ }^{34}$

A clear advantage of dehulling is the concomitant reduction of the concentration of antinutrients. ${ }^{15,16}$ However, the fate of the minerals after dehulling is not always reported in most studies involving legumes. In Bambara groundnuts, dehulling could reduce the concentrations of antinutrients concentrated in the seed coat $^{15}$ without remarkably influencing the $\mathrm{Mg}, \mathrm{Fe}$ and $\mathrm{Zn}$ concentrations but reducing that of $\mathrm{Ca}$.

3.1.3 Influence of soaking and cooking. A soaking treatment of $16 \mathrm{~h}$ at room temperature was performed prior to the cooking treatment. Each mineral showed its own distinct behaviour due to the applied treatments (Table 1). Soaking of whole and dehulled seeds did not result in notable changes in the Ca concentration (1-2\% decrease from the initial concentration) (Table 1). Regression analysis showed that soaking was not a significant factor affecting $\mathrm{Ca}$ concentration (Table 3). However, a decrease in the $\mathrm{Ca}$ concentration (22-29\%) occurred upon cooking of the dehulled samples for $60 \mathrm{~min}$ (compared with the concentration after soaking) (Table 1). Only limited $\mathrm{Ca}$ continues to leach out at $120 \mathrm{~min}$. This was statistically confirmed as both dehulling and cooking treatments were significant and interacting factors (Table 3). The seed coat may protect against $\mathrm{Ca}$ leaching by binding $\mathrm{Ca}^{38}$ or may act as a physical barrier to the loss of solids during cooking.

For $\mathrm{Mg}$, the soaking treatment decreased the initial concentration by $2 \%$ and $10 \%$ for 0 week and 32 week whole samples, respectively. For the dehulled samples, soaking resulted in an even more pronounced degree of $\mathrm{Mg}$ leaching. The $\mathrm{Mg}$ concentration decreased by $36 \%$ and $56 \%$ after soaking 0 weekdehulled and 32 week-dehulled samples, respectively (calculated from Table 1). The seed coat probably protects against some electrolyte leakage during soaking as also observed in the case of Ca. Soaking alone and soaking after a dehulling treatment were the most significant treatments (Table 3). In the particular case of $\mathrm{Mg}$, storage had an effect on the leaching potential during soaking, as a sharper decrease in the $\mathrm{Mg}$ concentration was observed for aged samples (16 weeks and 32 weeks). We noted a general increase in the loss of solids (solids potentially contain leached minerals) in the evaporated soaking water for the aged samples compared to the fresh samples. An increase from 0.23 to $1.6 \mathrm{mg}$ solids per $\mathrm{mL}$ soaking water was noted in the soaking water of fresh and aged seeds, respectively. Higher solute and electrolyte leakage during soaking occurred in aged as compared to fresh Faba beans (18-36 $\mathrm{mg} \mathrm{g}^{-1}$ vs. 4-7 $\left.\mathrm{mg} \mathrm{g}^{-1}\right) .{ }^{39}$

In both whole and dehulled Bambara groundnuts, the $\mathrm{Mg}$ concentration further decreased with cooking time (Table 3).

After cooking ( $2 \mathrm{~h}$ ), between 26 and $43 \%$ of $\mathrm{Mg}$ leached out from the whole seeds, whereas in the dehulled samples, the $\mathrm{Mg}$ concentration decreased between 66 and 74\%. Such considerable losses of $\mathrm{Mg}$ as a result of soaking and cooking have also been reported in whole common beans $(40 \%) .{ }^{40}$ The relatively easy leaching of $\mathrm{Mg}$ suggests that it might be loosely chelated to matrix constituents and thus readily solubilises into the soaking and cooking water.

The Fe concentration ranged between 3.4 and $4.9 \mathrm{mg}$ per $100 \mathrm{~g} \mathrm{dw}$ of whole seeds and was between 2.7 and $4.3 \mathrm{mg}$ per 
$100 \mathrm{~g} \mathrm{dw}$ for dehulled seeds, when considering all treatments. The initial Fe concentration decreased by $28 \%$ due to soaking, and this treatment was the only main effect. Non-ferritin Fe is known to be preferentially bound to phytic acid. ${ }^{41}$ The complexes formed are probably not readily soluble and this minimises the extent of leaching of Fe during soaking and cooking.

The $\mathrm{Zn}$ concentration decreased during soaking (9\%) and cooking (29\%) in both whole and dehulled Bambara groundnuts, and both treatments were significant main effects (Table 3). However, for both Fe and $\mathrm{Zn}$, the regression analysis could not sufficiently explain the variation in the data (low $R^{2}$ adj). This could have been due to the low variability of the experimental data of $\mathrm{Fe}$ and $\mathrm{Zn}$ concentrations as affected by the different treatments, as shown in Table 1.

3.1.4 Influence of prolonging the cooking time as a result of storage-induced ageing. Legume ageing has an effect on their cooking behaviour. In practice, it becomes essential to adapt the cooking time in order to achieve a certain desired palatable hardness, which can, of course, be consumer dependent. ${ }^{27}$ We, therefore, analysed mineral concentrations after adapting cooking times of whole aged Bambara groundnuts to achieve similar palatability to the fresh sample. It can be questioned whether this adaptation of cooking time would affect the mineral concentrations in the legume, considering different postharvest storage levels.

Amongst the analysed minerals, $\mathrm{Mg}$ showed the most striking observation; its concentration decreased due to the necessary extension of the cooking time required for the aged samples (16 weeks and 32 weeks) (Fig. 1). For the 32 week sample, a further decrease of $50 \%$ in the $\mathrm{Mg}$ concentration occurred, when the cooking time was extended from $120 \mathrm{~min}$ to $300 \mathrm{~min}$. This is consistent with what was already pointed out in section 3.1.3, where soaking and cooking were significant factors determining the final concentration of $\mathrm{Mg}$. Overall, soaking and then cooking of the aged whole seeds for $300 \mathrm{~min}$ (32 weeks-300 $\mathrm{min}$ ) decreased the initial Mg concentration by $72 \%$. In contrast, a fresh sample cooked for $120 \mathrm{~min}$ (0 weeks-120 min), but possessing comparable palatability, only lost $26 \%$ of the initial $\mathrm{Mg}$ concentration. For Fe and $\mathrm{Zn}$, an overall decrease of $57 \%$ and $48 \%$, respectively, occurred when the cooking time was extended to $300 \mathrm{~min}$. Ca concentrations were only marginally changed by the prolonged cooking time (from 49.9 to $46.3 \mathrm{mg}$ per $100 \mathrm{~g} \mathrm{dw}$ as the cooking time extended from $120 \mathrm{~min}$ to $300 \mathrm{~min}$ ).

In most food applications, the cooking water will indeed be discarded before consumption. If this is not the case, e.g. when included in a soup product, it would be possible to obtain higher concentrations of the minerals than when in the former case.

\subsection{Insight into complexation of minerals as affected by storage}

3.2.1 Effect of storage-induced ageing on the solubility of $\mathrm{Ca}, \mathbf{M g}, \mathbf{F e}$ and $\mathbf{Z n}$. One of the questions in this study was whether storage-induced ageing could influence mineral chelation, as implied by pectin-cation-phytate HTC theory. Accordingly, the solubility of $\mathrm{Ca}, \mathrm{Mg}$, Fe or $\mathrm{Zn}$ was determined from the milled 0 week, 16 week and 32 week samples. It was revealed that the change in the percentage of soluble minerals with storage depends on the mineral in question.

The solubility of $\mathrm{Ca}$ in fresh whole samples ( 0 weeks) was $52 \%$, and it decreased with ageing (32 weeks) to $30 \%$ (Fig. 2). The possible reason for this observation is discussed in more detail in section 3.2.2. $\mathrm{Mg}$ and $\mathrm{Zn}$ had the highest solubility
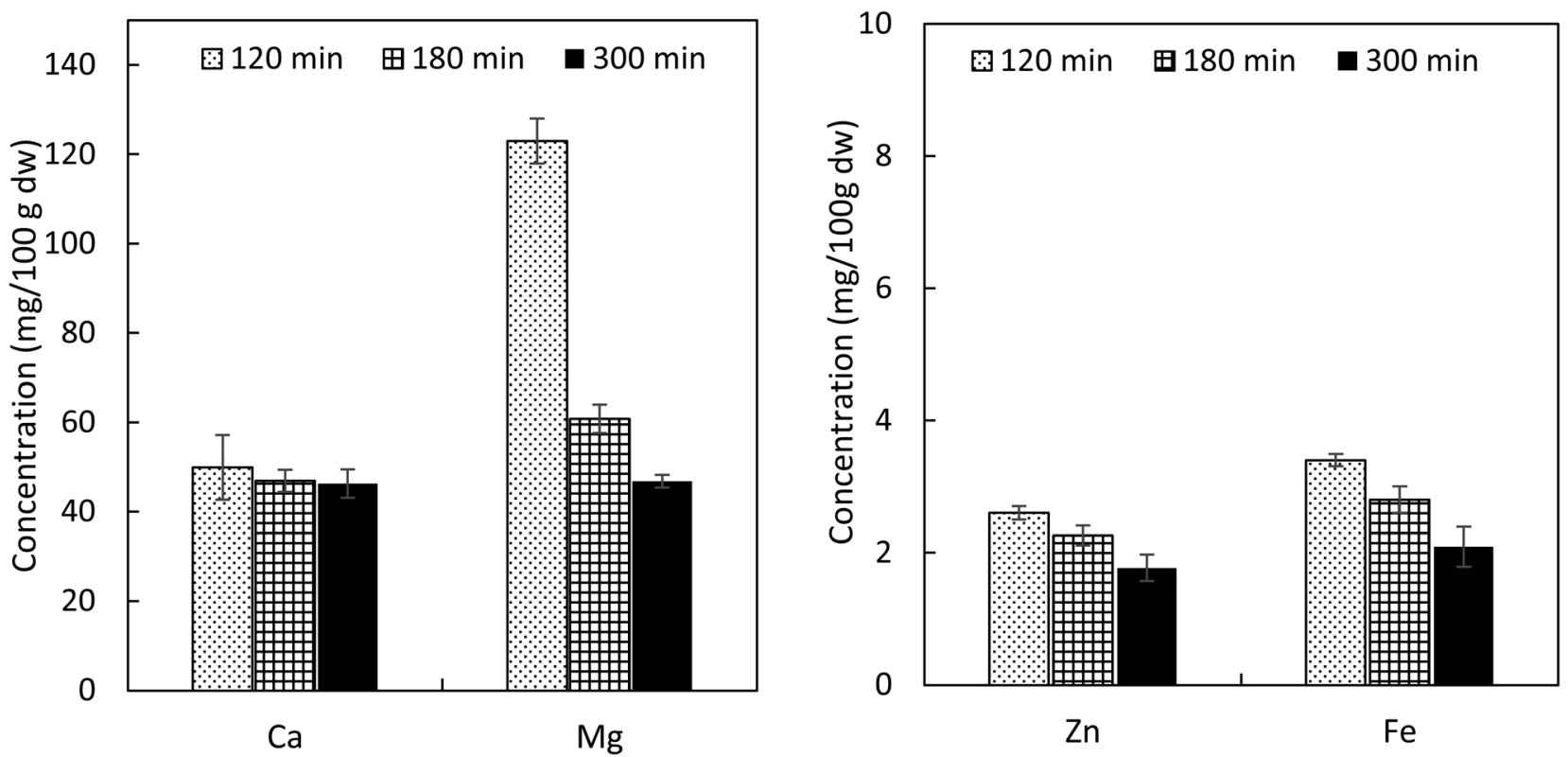

Fig. 1 Concentration of $\mathrm{Ca}, \mathrm{Mg}, \mathrm{Fe}$ and $\mathrm{Zn}$ in whole Bambara groundnuts after adapting cooking time for aged samples to obtain comparable palatability. 

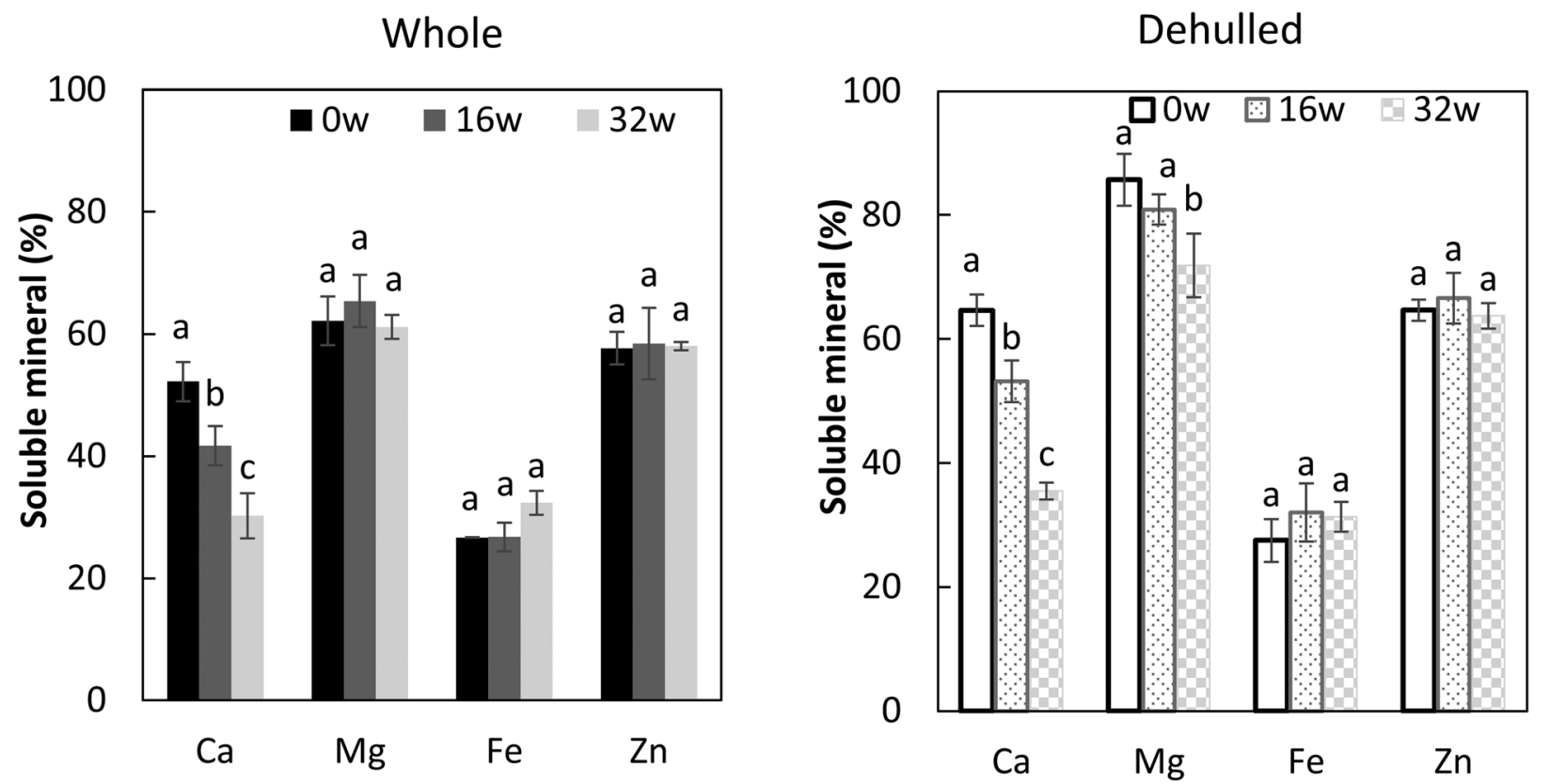

Fig. 2 Solubility of $\mathrm{Ca}, \mathrm{Mg}, \mathrm{Fe}$ and $\mathrm{Zn}$ in the supernatants of fresh and aged ( 0 weeks, 16 weeks and 32 weeks) Bambara groundnuts. Different letters $(a-c)$ show differences due to the effect of storage time for each mineral.

(65\%). Fe solubility was low (32\%). In general, the solubility of $\mathrm{Mg}, \mathrm{Zn}$, and Fe seemed to be limitedly affected by ageing. Mineral solubility increased for dehulled samples (percentage increase was $\sim 17 \%$ for $\mathrm{Ca}, \sim 21 \%$ for $\mathrm{Mg}, \sim 8 \%$ for $\mathrm{Fe}$ and $\sim 9 \%$ for $\mathrm{Zn})$. This increase can be attributed to the potential reduction in the antinutrients by seed coat removal. The seed coat of legumes is reported to be rich in antinutrients. ${ }^{4,5,8}$ At the $\mathrm{pH}$ used, we do not expect phytates or polyphenols to be solubilised as they require acidic conditions to be solubilised. ${ }^{42}$ Many antinutrients present in Bambara groundnuts, for instance, pectin, phytic acid and polyphenols, have different abilities to chelate minerals. ${ }^{43}$ While these have different abilities for binding minerals, different minerals bind to varying extents to one antinutrient as well. ${ }^{44}$ Typically, $\mathrm{Fe}$ is known to be strongly chelated to phytic acid in legumes and cereal seeds. ${ }^{12}$ Based on our observations discussed above, it was found that $\mathrm{Mg}$ and $\mathrm{Zn}$ seem to be relatively loosely bound to antinutrients in milled Bambara groundnuts, given their ease of solubility.

3.2.2 Fluorescence labelling of cotyledon sections to visualise Ca crosslinked pectin. The apparent reduction (36\%) in the solubility of Ca with storage time (Fig. 2) suggests that more and more Ca was bound to matrix constituents as ageing proceeded as implied by the pectin-cation-phytate hypothesis. Therefore, an experiment was set up to visualise Ca crosslinked pectin in the cell walls of raw fresh and aged sampled after in situ immunolabelling with the 2F4 monoclonal antibody. Fluorescently labelled Ca crosslinked pectin could be clearly visualised in the intercellular spaces for both the fresh and aged samples (Fig. 3). However, in the aged samples (16 weeks and 32 weeks) much more fluorescence of the Ca-pectin crosslinks could be seen in the intercellular spaces and also along
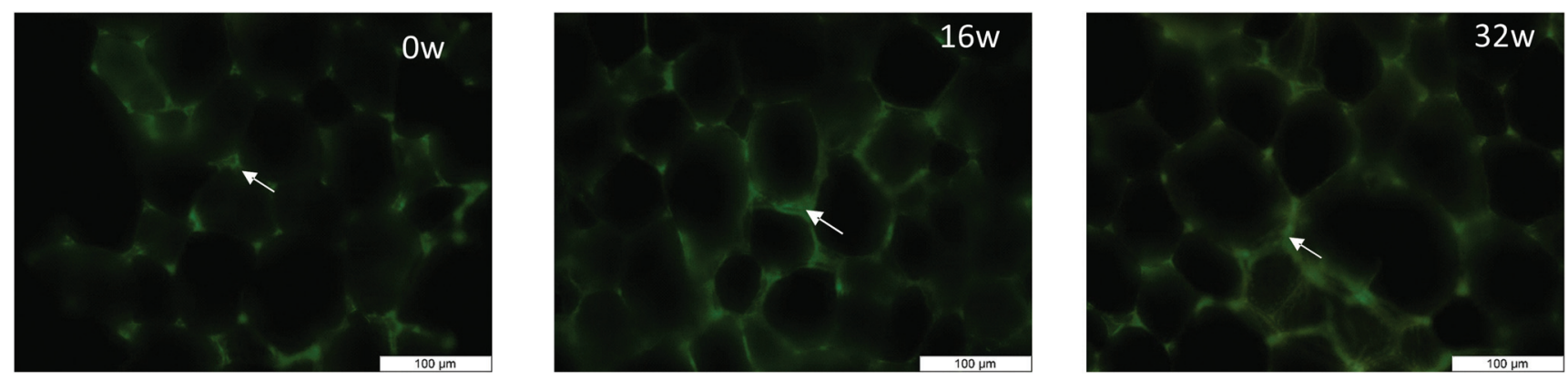

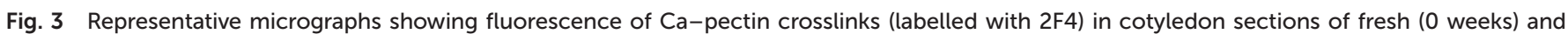

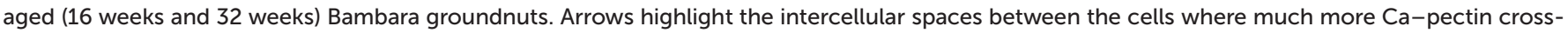
links were present in aged samples. 
the cell wall. Storage-induced ageing seemed to promote pectin-Ca crosslinks both in the intercellular spaces and along the cell wall.

Ca mediated pectin crosslinks, which promote cell adhesion and strength in plant cell walls, have been widely studied. $^{45} \mathrm{Ca}$ infused low-temperature blanched broccoli cortex sections that were treated with $2 \mathrm{~F} 4$ showed intense fluorescence in the intercellular spaces and along the cell wall, which was not present in blanched tissues without $\mathrm{Ca}$ infusion. ${ }^{31}$ These authors linked the higher fluorescence of $\mathrm{Ca}-$ pectin crosslinks noted in the $\mathrm{Ca}$ infused broccoli to higher texture stability during thermal processing. A previous study with the same batch of Bambara groundnuts aged under the same conditions ${ }^{27}$ demonstrated that the aged seeds required prolonged cooking time (300 $\mathrm{min}$ ) compared to the fresh seeds $(120 \mathrm{~min})$. In that work, it was hypothesised that the extended cooking time was necessary partly because of the increased formation of $\mathrm{Ca}$ crosslinks that strengthened the middle lamella, which can now be visualised here.

Other HTC hypotheses may also contribute to these observations. For instance, the membrane damage due to lipid oxidation may facilitate the migration of minerals to the cell wall and into the junction zones. ${ }^{46}$ It is also possible that the preparatory soaking done before obtaining the sections may have allowed more efficient diffusion of minerals into the cell walls. Nonetheless, X-ray spectroscopic evidence of cowpeas (without any soaking) illustrated that more $\mathrm{Ca}$ is bound in the middle lamella of the cell walls of HTC cowpeas compared to fresh ones. $^{22}$ The reduction of Ca solubility with storage time (Fig. 2) was observed in milled flours and the microscopic images depicted in Fig. 3 are from cotyledon sections. Nevertheless, we do not believe that the milling disturbed the electrostatic interactions between pectin and $\mathrm{Ca}$.

3.2.3 Degree of methylesterification. The DM was determined from the cotyledon sections of raw (fresh and aged) Bambara groundnuts, to obtain information on one of the characteristics of the pectin that is closely related to the formation of Ca crosslinks. The DM of the fresh Bambara groundnuts was about $58 \%$, but by 32 weeks of storage, it decreased to $47 \%$. Similar ranges of DM have been reported for common beans. ${ }^{40}$ Due to the humid storage conditions (78\% RH), the moisture content of the Bambara groundnut samples increased from $9 \%$ (at 0 weeks) to $14 \%$ (at 32 weeks). It is possible that enzyme activities, including that of pectin methylesterase, increased under the experimental storage conditions and may have resulted in the slight demethylesterification that is noted. This decrease in DM may have caused an increase in the amount of $\mathrm{Ca}$ that crosslinked to pectin or promoted the strength of interaction during ageing and thereby reducing $\mathrm{Ca}$ solubility (Fig. 2). The DM quantified here shows that the pectin in situ still possesses the potential for its free carboxylic groups to participate in further crosslinking with Ca. We only measured the DM since it was not the focus of this work to characterise the nature of the pectin. However, the DM is not the only factor influencing ionic pectin crosslinks. The degree of blockiness and the presence of side chains are other essen- tial factors that may affect the crosslinking of pectin. ${ }^{47}$ Since the HTC involves multiple mechanisms, other complex crosslinks involving $\mathrm{Ca}$, e.g., pectin-Ca-ferulic acid crosslinks, could potentially exist. ${ }^{38}$ Furthermore, membrane damage that occurs in the aged samples ${ }^{46}$ could also promote the formation of ionic pectin crosslinks (more ions migrating to the cell wall without changes in the DM). Taken together, the results of solubility, microscopy and DM suggest that as storage-induced ageing takes place, Ca becomes much more strongly bound to pectin.

\subsection{Influence of treatments on the bioaccessibility of $\mathrm{Ca}, \mathrm{Mg}$, Fe and $\mathrm{Zn}$}

It is essential to know how much of a mineral could be available for uptake (i.e., bioaccessible), considering the changes in the concentration of minerals after the different processing steps. Thus the in vitro bioaccessibility (\%) of $\mathrm{Ca}, \mathrm{Mg}, \mathrm{Zn}$ or $\mathrm{Fe}$ was analysed. Bioaccessibility of the minerals was never $100 \%$, which shows that there is always some level of mineral chelation. The influence of the treatments on in vitro bioaccessibility was mineral dependent (Fig. 4). The impact of the different treatments considered on mineral bioaccessibility was evaluated by regression analysis (per mineral type) (Table 4). In this case, for treatments, we included storage time, dehulling and cooking time as these are relevant factors considered during the processing of legumes before consumption. People will not consume raw legumes; however, we included the results for raw samples in the analysis in order to assess the changes induced by the treatments. The results for each mineral are discussed below.

3.3.1 Ca bioaccessibility. Dehulling improved the bioaccessibility of $\mathrm{Ca}$; dehulled cotyledons of Bambara groundnuts had a higher Ca bioaccessibility (17-29\% increase) compared to the whole seeds (Fig. 4). In fact, dehulling had the most significant effect on Ca bioaccessibility, followed by storage time (Table 4). Removal of the seed coats may have reduced the level of antinutrients that chelate $\mathrm{Ca}$, as shown in other studies. $^{15}$

The bioaccessibility of Ca decreased from 55\% (for fresh whole seeds) to $31 \%$ (for 32 weeks aged seeds), due to storageinduced ageing (Fig. 4). This decrease is consistent with the reduction of Ca solubility as a function of storage time (section 3.2.1). Pectin is likely a predominant factor in influencing $\mathrm{Ca}$ bioaccessibility in Bambara groundnuts, and possibly in legumes in general as more $\mathrm{Ca}$-pectin crosslinks for the aged samples were clearly shown (Fig. 3). The link between Camediated pectin interactions and bioaccessibility has been demonstrated for tomato-based suspensions, amongst other vegetable matrices, with $\mathrm{Ca}$ bioaccessibility decreasing with increasing electrostatic interactions between pectin and $\mathrm{Ca}^{24}$ Additionally, the cooking time (60 $\mathrm{min}$ and $120 \mathrm{~min}$ ) significantly improved the bioaccessibility of Ca (increase between 14 and $18 \%$ ). This is likely due to the reduction of the concentration of antinutrients (e.g., oxalates, tannins and phytates) during cooking. ${ }^{16,21,48}$ A wide range of Ca bioaccessibility values are reported. In red kidney beans, peas and lentils, $\mathrm{Ca}$ 

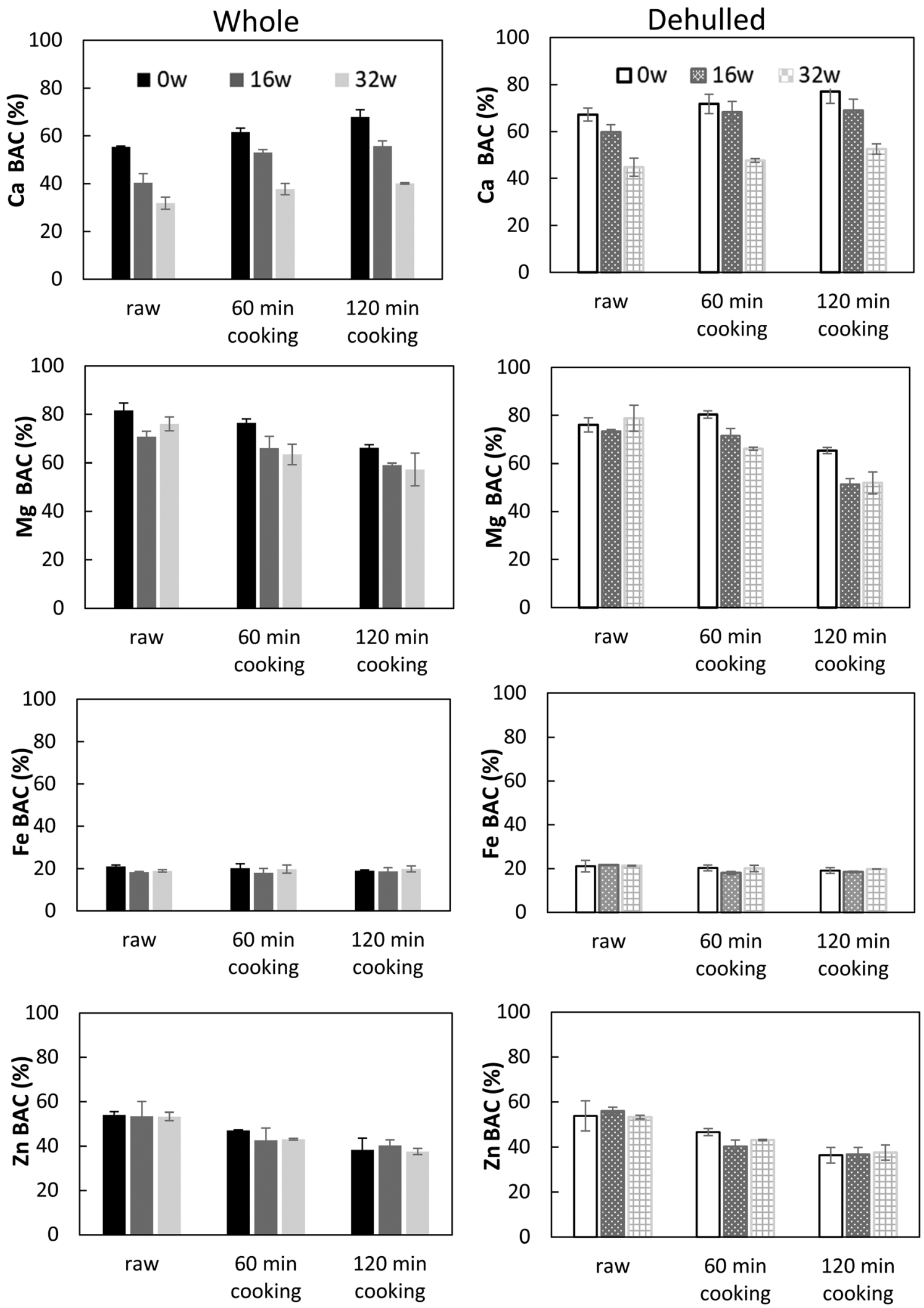

Fig. 4 Bioaccessible $\mathrm{Ca}, \mathrm{Mg}$, Fe and $\mathrm{Zn}$ in Bambara groundnuts stored for 0,16 or 32 weeks, evaluated as a function of cooking time (raw) or 60 and 120 min of the whole (left) or dehulled (right). 
Table 4 Regression coefficients ( \pm error) of the variables (storage time, dehulling and cooking treatments) influencing the bioaccessibility of $\mathrm{Ca}$, $\mathrm{Mg}$, Fe or Zn. Significance was tested within $95 \%$ confidence intervals

\begin{tabular}{llllll}
\hline $\begin{array}{l}\text { Mineral } \\
\text { type }\end{array}$ & Intercept & $\begin{array}{l}\text { Storage } \\
\text { time }\end{array}$ & Dehulling & $\begin{array}{l}\text { Cooking } \\
\text { time }\end{array}$ & $R^{2}$ adj \\
\hline $\mathrm{Ca}$ & $62.0 \pm 1.4$ & $-0.8 \pm 0.1$ & $-6.33 \pm 0.1$ & $-0.09 \pm 0.0$ & 0.95 \\
$\mathrm{Mg}$ & $82.7 \pm 2.0$ & $-0.3 \pm 0.1$ & n.s & $-0.15 \pm 0.1$ & 0.80 \\
$\mathrm{Fe}$ & $21.1 \pm 0.1$ & n.s & n.s & n.s & - \\
$\mathrm{Zn}$ & $54.4 \pm 0.1$ & n.s & n.s & $-0.13 \pm 0.1$ & 0.92 \\
n.s - not significant. & & & & &
\end{tabular}

bioaccessibility values were $28 \%, 42 \%$ and $59 \%$, respectively. ${ }^{49}$ In particular cases, even lower $\mathrm{Ca}$ bioaccessibility values $(<10 \%)$ have been reported for both fresh and aged cowpeas. ${ }^{22}$

3.3.2 $\mathrm{Mg}$ bioaccessibility. $\mathrm{Mg}$ is the most bioaccessible mineral amongst the minerals (raw samples) studied (83\%), and the bioaccessibility decreased to $66 \%$ by cooking for $2 \mathrm{~h}$ (Fig. 4). $\mathrm{Mg}$ bioaccessibility was also considerably influenced by ageing (Table 4). The concentration of $\mathrm{Mg}$ reduced after soaking and cooking time due to leaching, especially for aged and dehulled samples (section 3.1.3). The remaining fraction may be relatively more chelated than the fraction that leached out, thus the apparent decrease in bioaccessibility with storage and cooking time. $\mathrm{Mg}$ has similarly been found to be more bioaccessible compared to other minerals in citrus residues $(94 \%)^{50}$ as well in pectin model systems $(87 \%),{ }^{51}$ suggesting that it naturally exists in a readily bioaccessible state in various plant-based food. It could also be that the antinutrients present possess a lower affinity for $\mathrm{Mg}$ as compared to the other minerals studied here. ${ }^{51} \mathrm{Mg}$ bioaccessibility was not significantly improved by dehulling.

3.3.3 Fe bioaccessibility. Fe bioaccessibility was low (18-25\%) (Fig. 4), and none of the treatments reduced or improved the bioaccessibility significantly (Table 4). The low bioaccessibility was consistent with the solubility of Fe, which was also low (32\%). Varying values of Fe bioaccessibility are reported depending on the type of legume. Bioaccessibility of Fe in cooked white beans was $43 \%,{ }^{7}$ while the bioaccessibility of Fe in red kidney beans, green peas and lentils was 9\%, 25\% and $33 \%$, respectively. ${ }^{49}$ Even lower bioaccessibility values $(<1 \%)$ have been reported for fresh and aged cowpeas. ${ }^{22}$ Although antinutrients were not characterised in this work, numerous studies have demonstrated that phytic acid largely inhibits the release of $\mathrm{Fe}$ from legume matrices. ${ }^{23,41}$ Differences in mineral bioaccessibility values may also be due to the type of separation technique used after digestion, i.e., dialysis or centrifugation.

3.3.4 Zn bioaccessibility. Zn bioaccessibility decreased from $54 \%$ to $38 \%$ by cooking whole seeds for $2 \mathrm{~h}$ (Fig. 4). Cooking time was the only significant factor influencing $\mathrm{Zn}$ bioaccessibility (Table 4). The trend of $\mathrm{Zn}$ bioaccessibility decreasing with cooking time has been observed in some legumes. ${ }^{52}$ For instance, the bioaccessibility of $\mathrm{Zn}$ in chickpeas and cowpeas decreased by $11 \%$ and $63 \%$, respectively, after microwave cooking. ${ }^{53}$ According to the study on chickpeas and cowpeas, the decrease in $\mathrm{Zn}$ bioaccessibility due to cooking time was attributed to the complexation of $\mathrm{Zn}$ with proteins. As whole legumes are cooked, both the starch and proteins become enclosed within the cell walls. Upon cooking, proteins denature, and this greatly reduces their solubility. ${ }^{54}$ Perhaps due to the encapsulation of the aggregated protein and starch granules in the cotyledon cells, the release of $\mathrm{Zn}$ thus decreases with cooking time. In contrast, the raw milled sample, with opened up cells, where the proteins were not encapsulated by the cell walls, had higher bioaccessibility as well as solubility values (section 3.2.1).

\subsection{Estimated contribution towards the daily RNI}

The contribution towards the RNI was established based on a $130 \mathrm{~g}$ serving of cooked fresh or aged whole Bambara groundnuts. A serving of Bambara groundnuts could potentially provide $3 \%$ of $\mathrm{Ca}, 24 \%$ of $\mathrm{Mg}, 9 \%$ of $\mathrm{Zn}$ and $8 \%$ of $\mathrm{Fe}$ to the daily RNI. Based on the in vitro bioaccessibility results presented in section 3.3, the contribution to the RNI after factoring in bioaccessibility values will be much lower. As such, a serving of Bambara groundnuts (wet basis) seems to contribute very little to the daily RNI of these minerals.

\section{Conclusions}

The present study was designed to investigate the effects of storage-induced ageing, dehulling, soaking and cooking time on the concentration of (free/chelated) $\mathrm{Ca}, \mathrm{Mg}, \mathrm{Fe}$ and $\mathrm{Zn}$ and their in vitro bioaccessibility in Bambara groundnuts. Ageing has a profound effect on the solubility and bioaccessibility of some minerals (especially $\mathrm{Ca}$ ) and is a relevant factor to consider when assessing the mineral bioaccessibility of legumes. Dehulling influences mineral concentrations based on the level of accumulation of that mineral in the seed coat. The extent to which minerals leach during soaking and cooking is hypothesised to be determined by the degree to which a mineral is bound in the matrix. While Bambara groundnuts are regarded as a rich source of minerals (on a dry weight basis), the bioaccessibility of these minerals is mostly low after processing. Besides, it seems that it is rather unfeasible to affect these values through treatments studied in this work. The contribution of a serving of Bambara groundnuts hardly meets the RNI requirements, and therefore populations relying on this legume may still be at risk for mineral deficiencies. This research opens the way to study the effect of ageing on the bioaccessibility of minerals in other legume matrices. It would be interesting to evaluate which antinutrients are mostly responsible for the chelation of specific minerals in the legume matrix. Finally, evaluation of the role of fermentation of the matrix by the gut microbiota on the mineral release in the colon could be another fruitful area of research. 


\section{Conflicts of interest}

There are no conflicts to declare.

\section{Acknowledgements}

S. Gwala is a PhD fellow funded by the Interfaculty Council for Development Cooperation (IRO). I. Wainaina is a PhD Fellow funded by VLIR-UOS. C. Kyomugasho is a postdoctoral researcher funded by The Research Foundation Flanders (FWO). The authors gratefully acknowledge the support from the KU Leuven Research Fund and the FWO Project Grant (G054217N).

\section{References}

1 E. Huskisson, S. Maggini and M. Ruf, The Role of Vitamins and Minerals in Energy Metabolism and Well-Being, 2007, vol. 35.

2 J. P. Schuchardt and A. Hahn, Intestinal Absorption and Factors Influencing Bioavailability of Magnesium-An Update, Curr. Nutr. Food Sci., 2017, 13, 260-278.

3 J. P. Goff, Invited review: Mineral absorption mechanisms, mineral interactions that affect acid-base and antioxidant status, and diet considerations to improve mineral status, J. Dairy Sci., 2018, 101, 2763-2813.

4 K. Raes, D. Knockaert, K. Struijs and J. Van Camp, Role of processing on bioaccessibility of minerals: Influence of localization of minerals and anti-nutritional factors in the plant, Trends Food Sci. Technol., 2014, 37, 32-41.

5 A.-S. Sandberg, Bioavailability of minerals in legumes, Br. J. Nutr., 2002, 88, 281.

6 S. Rousseau, C. Kyomugasho, M. Celus, M. E. G. Hendrickx and T. Grauwet, Barriers impairing mineral bioaccessibility and bioavailability in plant-based foods and the perspectives for food processing, Crit. Rev. Food Sci. Nutr., 2019, 118.

7 M. A. Faria, A. Araújo, E. Pinto, C. Oliveira, M. T. OlivaTeles, A. Almeida, C. Delerue-Matos and I. Ferreira, Bioaccessibility and intestinal uptake of minerals from different types of home-cooked and ready-to-eat beans, J. Funct. Foods, 2018, 50, 201-209.

8 M. Oghbaei and J. Prakash, Effect of primary processing of cereals and legumes on its nutritional quality: A comprehensive review, Cogent Food Agric., 2016, 2, 1.

9 A. Sahuquillo, R. Barberá and R. Farré, Bioaccessibility of calcium, iron and zinc from three legume samples, Food/ Nahrung, 2003, 47, 438-441.

10 L. A. Garcia-Vela, J. M. del Valle and D. W. Stanley, Hard-toCook Defect in Black Beans: The Effect of Soaking in Various Aqueous Salt Solutions, Can. Inst. Food Sci. Technol. J., 1991, 24, 60-67.

11 M. Brune, L. Rossander-Hultén, L. Hallberg, A. Gleerup and A.-S. Sandberg, Iron Absorption from Bread in
Humans: Inhibiting Effects of Cereal Fiber, Phytate and Inositol Phosphates with Different Numbers of Phosphate Groups, J. Nutr., 1992, 122, 442-449.

12 R. F. Hurrell, M. B. Reddy, M.-A. Juillerat and J. D. Cook, Degradation of phytic acid in cereal porridges improves iron absorption by human subjects, Am. J. Clin. Nutr., 2003, 77, 1213-1219.

13 C. Reyes-Moreno, O. Paredes-López and E. Gonzalez, Hardto-cook phenomenon in common beans-A review, Crit. Rev. Food Sci. Nutr., 1993, 33, 227-286.

14 S. Van Buggenhout, D. N. Sila, T. Duvetter, a. Van Loey and M. Hendrickx, Pectins in Processed Fruits and Vegetables: Part III-Texture Engineering, Compr. Rev. Food Sci. Food Saf., 2009, 8, 105-117.

15 C. A. Nti, Effects of bambara groundnut (Vigna subterranea) variety and processing on the quality and consumer appeal for its products, Int. J. Food Sci. Technol., 2009, 44, 2234-2242.

16 A. E. Mubarak, Nutritional composition and antinutritional factors of mung bean seeds (Phaseolus aureus) as affected by some home traditional processes, Food Chem., 2005, 89, 489-495.

17 S. Hemalatha, S. Gautam, K. Platel and K. Srinivasan, Influence of exogenous iron, calcium, protein and common salt on the bioaccessibility of zinc from cereals and legumes, J. Trace Elem. Med. Biol., 2009, 23, 75-83.

18 O. R. Adeleke, O. Q. Adiamo and O. S. Fawale, Nutritional, physicochemical, and functional properties of protein concentrate and isolate of newly-developed Bambara groundnut (Vigna subterrenea L.) cultivars, Food Sci. Nutr., 2018, 6, 229-242.

19 R. Azman Halimi, B. J. Barkla, S. Mayes and G. J. King, The potential of the underutilized pulse bambara groundnut (Vigna subterranea (L.) Verdc.) for nutritional food security, J. Food Compos. Anal., 2019, 77, 47-59.

20 J. Parada and J. M. Aguilera, Food Microstructure Affects the Bioavailability of Several Nutrients, J. Food Sci., 2007, 72, R21-R32.

21 U. S. Ndidi, C. U. Ndidi, I. A. Aimola, O. Y. Bassa, M. Mankilik and Z. Adamu, Effects of Processing (Boiling and Roasting) on the Nutritional and Antinutritional Properties of Bambara Groundnuts (Vigna subterranea [L.] Verdc.) from Southern Kaduna, Nigeria, J. Food Process., 2014, 2014, 1-9.

22 J. Kruger, R. Minnis-Ndimba, C. Mtshali and A. Minnaar, Novel in situ evaluation of the role minerals play in the development of the hard-to-cook (HTC) defect of cowpeas and its effect on the in vitro mineral bioaccessibility, Food Chem., 2015, 174, 365-371.

23 M. Gabaza, H. Shumoy, M. Muchuweti, P. Vandamme and K. Raes, Enzymatic degradation of mineral binders in cereals: Impact on iron and zinc bioaccessibility, J. Cereal Sci., 2018, 82, 223-229.

24 C. Kyomugasho, K. Willemsen, S. Christiaens, A. M. Van Loey and M. E. Hendrickx, Pectin-interactions and in vitro bioaccessibility of calcium and iron in particulated 
tomato-based suspensions, Food Hydrocolloids, 2015, 49, 164-175.

25 FAO, IFAD, UNICEF, WFP and WHO, The State of Food Security and Nutrition in the World 2018. Building climate resilience for food security and nutrition, Food and Agricultre Organisation of the United Nations, Rome, 2018.

26 R. K. Gupta, S. S. Gangoliya and N. K. Singh, J. Food Sci. Technol., 2013, 52, 676-684.

27 S. Gwala, I. Wainana, A. Pallares Pallares, C. Kyomugasho, M. Hendrickx and T. Grauwet, Texture and interlinked post-process microstructures determine the in vitro starch digestibility of Bambara groundnuts with distinct hard-tocook levels, Food Res. Int., 2019, 120, 1-11.

28 C. Kyomugasho, S. Christiaens, A. Shpigelman, A. M. Van Loey and M. E. Hendrickx, FT-IR spectroscopy, a reliable method for routine analysis of the degree of methylesterification of pectin in different fruit- and vegetablebased matrices, Food Chem., 2015, 176, 82-90.

29 R. O. Miller, in Handbook of reference methods for plant analysis, ed. Y. P. Kalra, Taylor \& Francis Group, LLC, Florida, 1998, pp. 53-56.

30 B. L. Ridley, M. A. O’Neill and D. Mohnen, Phytochemistry, 2001, 57, 929-967.

31 S. Christiaens, S. Van Buggenhout, E. Vandevenne, R. Jolie, A. M. Van Loey and M. E. Hendrickx, Towards a better understanding of the pectin structure-function relationship in broccoli during processing: Part II-Analyses with anti-pectin antibodies, Food Res. Int., 2011, 44, 2896-2906.

32 M. Minekus, M. Alminger, P. Alvito, S. Ballance, T. Bohn, C. Bourlieu, F. Carrière, R. Boutrou, M. Corredig, D. Dupont, C. Dufour, L. Egger, M. Golding, S. Karakaya, B. Kirkhus, S. Le Feunteun, U. Lesmes, A. MacIerzanka, A. MacKie, S. Marze, D. J. McClements, O. Ménard, I. Recio, C. N. Santos, R. P. Singh, G. E. Vegarud, M. S. J. Wickham, W. Weitschies and A. Brodkorb, A standardised static in vitro digestion method suitable for foodan international consensus, Food Funct., 2014, 5, 11131124.

33 FAO and WHO, Human Vitamin and Mineral Requirements: report of a joint FAO/WHO consultation, Bangkok, Thailand, 2004.

34 J. T. Moraghan and K. Grafton, Distribution of selected elements between the seed coat and embryo of two black bean cultivars, J. Plant Nutr., 2002, 25, 169-176.

35 A. D. Barnabas and H. J. Arnott, Bot. Gaz., 1990, 151, 331341.

36 M. van der Straten, W. G. Keltjens, A. C. Okoboi and E. Westphal, The calcium nutrition of bambara groundnut (Vigna subterranea (L.) Verdc.), Plant Soil, 1995, 176, 229234.

37 N. D. Ribeiro, S. M. Maziero, M. Prigol, C. W. Nogueira, D. P. Rosa and M. Possobom, Mineral concentrations in the embryo and seed coat of common bean cultivars, J. Food Compos. Anal., 2012, 26, 89-95.

38 G. Lombardi-Boccia, M. Lucarini, G. Di Lullo, E. Del Puppo, A. Ferrari and E. Carnovale, Dialysable, soluble and fermentable calcium from beans (Phaseolus vulgaris L.) as model for in vitro assessment of the potential calcium availability, Food Chem., 1998, 61, 167-171.

39 S. M. Nasar-Abbas, J. A. Plummer, K. H. M. Siddique, P. White, D. Harris and K. Dods, Cooking quality of faba bean after storage at high temperature and the role of lignins and other phenolics in bean hardening, LWT-Food Sci. Technol, 2008, 41, 1260-1267.

40 C. M. Chigwedere, C. M. Nkonkola, S. Rai, C. Kyomugasho, Z. J. Kermani, A. Pallares Pallares, A. M. Van Loey, T. Grauwet and M. E. Hendrickx, Cotyledon pectin molecular interconversions explain pectin solubilization during cooking of common beans (Phaseolus vulgaris), Food Res. Int., 2019, 116, 462-470.

41 K. L. Moore, I. Rodríguez-Ramiro, E. R. Jones, E. J. Jones, J. Rodríguez-Celma, K. Halsey, C. Domoney, P. R. Shewry, S. Fairweather-Tait and J. Balk, The stage of seed development influences iron bioavailability in pea (Pisum sativum L.), Sci. Rep., 2018, 8, 6865.

42 R. S. Bhatty and A. E. Slinkard, Relationship Between Phytic Acid and Cooking Quality in Lentil, Can. Inst. Food Sci. Technol. J., 1989, 22, 137-142.

43 F. Crea, C. De Stefano, D. Milea and S. Sammartano, Formation and stability of phytate complexes in solution, Coord. Chem. Rev., 2008, 252, 1108-1120.

44 S. Rousseau, C. Kyomugasho, M. Celus, N. Yeasmen, M. E. Hendrickx and T. Grauwet, Zinc bioaccessibility is affected by the presence of calcium ions and degree of methylesterification in pectin-based model systems, Food Hydrocolloids, 2019, 90, 206-215.

45 J. P. Knox, Cell adhesion, cell separation and plant morphogenesis, Plant J., 1992, 2, 137-141.

46 J. C. Richardson and D. W. Stanley, Relationship of Loss of Membrane Functionality and Hard-to-Cook Defect in Aged Beans, J. Food Sci., 1991, 56, 590-591.

47 M. Celus, C. Kyomugasho, A. M. Van Loey, T. Grauwet and M. E. Hendrickx, Influence of Pectin Structural Properties on Interactions with Divalent Cations and Its Associated Functionalities, Compr. Rev. Food Sci. Food Saf., 2018, 17, 1576-1594.

48 B. Viadel, R. Barberá and R. Farré, Calcium, iron and zinc uptakes by Caco-2 cells from white beans and effect of cooking, Int. J. Food Sci. Nutr., 2006, 57, 190-197.

49 J. Suliburska and Z. Krejpcio, Evaluation of the content and bioaccessibility of iron, zinc, calcium and magnesium from groats, rice, leguminous grains and nuts, J. Food Sci. Technol., 2014, 51, 589-594.

50 J. G. S. Silva, A. P. Rebellato, R. Greiner and J. A. L. Pallone, Bioaccessibility of calcium, iron and magnesium in residues of citrus and characterization of macronutrients, Food Res. Int., 2017, 97, 162-169.

51 C. Kyomugasho, S. Gwala, S. Christiaens, Z. J. Kermani, A. M. Van Loey, T. Grauwet and M. E. Hendrickx, Pectin nanostructure influences pectin-cation interactions and in vitro-bioaccessibility of $\mathrm{Ca} 2+, \mathrm{Zn} 2+, \mathrm{Fe} 2+$ and $\mathrm{Mg} 2+$-ions in model systems, Food Hydrocolloids, 2017, 62, 299-310. 
52 S. Hemalatha, K. Platel and K. Srinivasan, Influence of heat processing on the bioaccessibility of zinc and iron from cereals and pulses consumed in India, J. Trace Elem. Med. Biol., 2007, 21, 1-7.

53 J. M. Butkus, S. O'Riley, B. S. Chohan and S. Basu, Interaction of Small Zinc Complexes with Globular
Proteins and Free Tryptophan, Int. J. Spectrosc., 2016, 2016, 1-12.

54 M. Carbonaro, M. Cappelloni, S. Nicoli, M. Lucarini and E. Carnovale, Solubility-Digestibility Relationship of Legume Proteins, J. Agric. Food Chem., 1997, 45, 33873394 . 